\title{
Three Primary Cancers in a Veteran With Agent Orange and Agent Blue Exposures
}

\author{
2LT Haana McMurray, USA; and LCDR Raj Singaraju, MD, USN
}

A Vietnam War veteran's exposures likely contributed to his cancer diagnoses, but these associations are confounded by his substance use, particularly cigarette smoking.

\begin{abstract}
Haana McMurray is a Medical Student and Raj Singaraju is an Assistant Professor in the Department of Medicine, both at the Uniformed Services University of the Health Sciences in Bethesda, Maryland. Correspondence: Haana McMurray (haana.mcmurray @gmail.com)
\end{abstract}

Fed Pract. 2021;38(suppl 3). Published online August 12. doi:10.12788/fp.0161
$\mathrm{K}$ nown as the "6 rainbow herbicides," based on their identifying color on storage containers, the United States widely deployed the herbicides agents orange, green, pink, purple, white, and blue during the Vietnam War to deny the enemy cover and destroy crops. ${ }^{1}$ Unfortunately, all these herbicides were found to have contained some form of carcinogen. Agent Blue's active ingredient consisted of sodium cacodylate trihydrate $\left(\mathrm{C}_{2} \mathrm{H}_{6} \mathrm{AsNaO}_{2}\right)$, a compound that is metabolized into the organic form of the carcinogen arsenic before eventually converting into its relatively less toxic inorganic form. ${ }^{2}$ Agent Orange's defoliating agent is 2,3,7,8-tetrachlorodibenzo-p-dioxin (TCDD). All rainbow herbicides except Agent Blue were unintentionally contaminated with carcinogenic dioxins. Agent Blue contained the carcinogen cacodylic acid, an organoarsenic acid. Today, herbicides no longer contain polychlorinated dibenzo-p-dioxins such as TCDD or arsenic due to strict manufacturing restrictions. ${ }^{2,3}$ In the treatment of veteran populations, knowledge of the 6 rainbow herbicides' carcinogenic potential is important.

Between 1962 and 1971, the United States sprayed more than 45 million liters of Agent Orange on Vietnam and at least $366 \mathrm{~kg}$ of TCDD on South Vietnam. ${ }^{1,4}$ However, because Agent Orange was not a known carcinogen during the Vietnam War, records of exposure are poor. Additionally, individuals in Vietnam during this period were not the only ones exposed to this carcinogen as Agent Orange also was sprayed in Thailand and Korea. ${ }^{5}$ Even today there are still locations in Vietnam where Agent Orange concentrations exceed internationally acceptable levels. The Da Nang, Bien Hoa, and Phu Cat airports in Vietnam have been found to have dioxin levels exceeding 1000 ppt (parts of dioxin per trillion parts of lipid) toxicity equivalence in the soil. Although the Vietnam government is working toward decontaminating these and many other dioxin hotspots, residents in these locations are exposed to higher than internationally acceptable levels of dioxin. ${ }^{6}$

Despite receiving less media attention, Vietnam War veterans and Vietnamese soldiers and civilians were exposed to significant amounts of arsenic-based Agent Blue. Arsenic is a compound which has no environmental half-life and is carcinogenic humans if inhaled or ingested. ${ }^{2}$ Between 1962 and 1971, the United States distributed 7.8 million liters of Agent Blue containing $1,232,400 \mathrm{~kg}$ of arsenic across 300,000 hectares of rice paddies, 100,000 hectares of forest, and perimeters of all military bases during the Vietnam War. ${ }^{2,5}$ According to a review by Saha and colleagues, lower levels of arsenic exposure are associated with acute and chronic diseases, including cancers, of all organ systems. ${ }^{7}$

The following case presentation involves a Vietnam War veteran aged 70 years who was exposed to Agent Orange and developed 3 primary cancers, including cutaneous large B-cell nonHodgkin lymphoma (NHL), high-grade urothelial carcinoma, and anal carcinoma in situ. Epidemiologically, this is an uncommon occurrence as only $8 \%$ of cancer survivors in the United States have been diagnosed with $>1$ cancer. $^{8}$

With no family history of cancer, the development of multiple malignancies raises concern for a history of toxin exposure. This report of a Vietnam War veteran with multiple conditions found to be associated with Agent Orange exposure provides an opportunity to discuss the role this exposure may have on the development of a comprehensive list of medical conditions as described by the literature. Additionally, the potential contributions of other confounding toxin exposures such as cigarette smoking, excessive alcohol use, and potential Agent Blue exposure on our patients' health will be discussed.

\section{CASE PRESENTATION}

A male aged 70 years with Stage IV primary cutaneous large B-cell NHL, incompletely resected high-grade urothelial cancer, carcinoma in situ 
of the anal canal, and peripheral arterial disease (PAD) presented to the primary care clinic at the Washington DC Veterans Affairs Medical Center (DCVAMC) with concern for left leg ischemia. $\mathrm{He}$ also reported 2 large telangiectasias on his back for 6 months accompanied by lymphadenopathy and intermittent night sweats.

He was last seen at the DCVAMC 15 months prior after his twelfth dose of rituximab treatment for NHL. However, the patient failed to return for completion of his treatment due to frustration with the lengthy chemotherapy and followup process. Additionally, the patient's history included 3 failed arterial stents with complete nonadherence to the prescribed clopidogrel, resulting in the failure of 3 more subsequent graft placements. On presentation, the patient continued to report nonadherence with the clopidogrel.

The patient's medical history included coronary artery disease (CAD) status after 2 stents in the left anterior descending artery and 1 stent in the proximal circumflex artery placed 4 years prior. He also had a history of hypertension, type 2 diabetes mellitus (T2DM), amyloid light-chain (AL) amyloidosis, aortic aneurysm, cataracts, obesity, treated hepatitis B and C, and posttraumatic stress disorder. He had no family history of cancer or AL amyloidosis; however, he noted that he was estranged from his family.

His social history was notable for active cigarette smoking up to 3 packs per day for 40 years and consuming large quantities of alcohol-at one point as many as 20 beers per day over a period of 4.5 years. He had a distant history of cocaine use but no current use, which was supported with negative urinary toxicology screens for illicit drugs over the past year.

Our patient also reported a history of Agent Orange exposure. As an artilleryman in the US Army III Corps, he was deployed for about 1 year in the most heavily sprayed regions of Vietnam, including Bien Hua, Long Binh, Xuan Loc, and Camp Zion for about 2 to 4 months at each location.

\section{Hospital Course}

The patient was treated on an inpatient basis for expedited workup and treatment for his urothelial carcinoma, NHL, and ischemic limb. His urothelial carcinoma was successfully resected, and the telangiectasias on his back were biopsied and found to be consistent with his known cutaneous large B-cell NHL, for which plans to resume outpatient chemotherapy were made.
FIGURE Most Heavily Sprayed Regions of Vietnam24,a

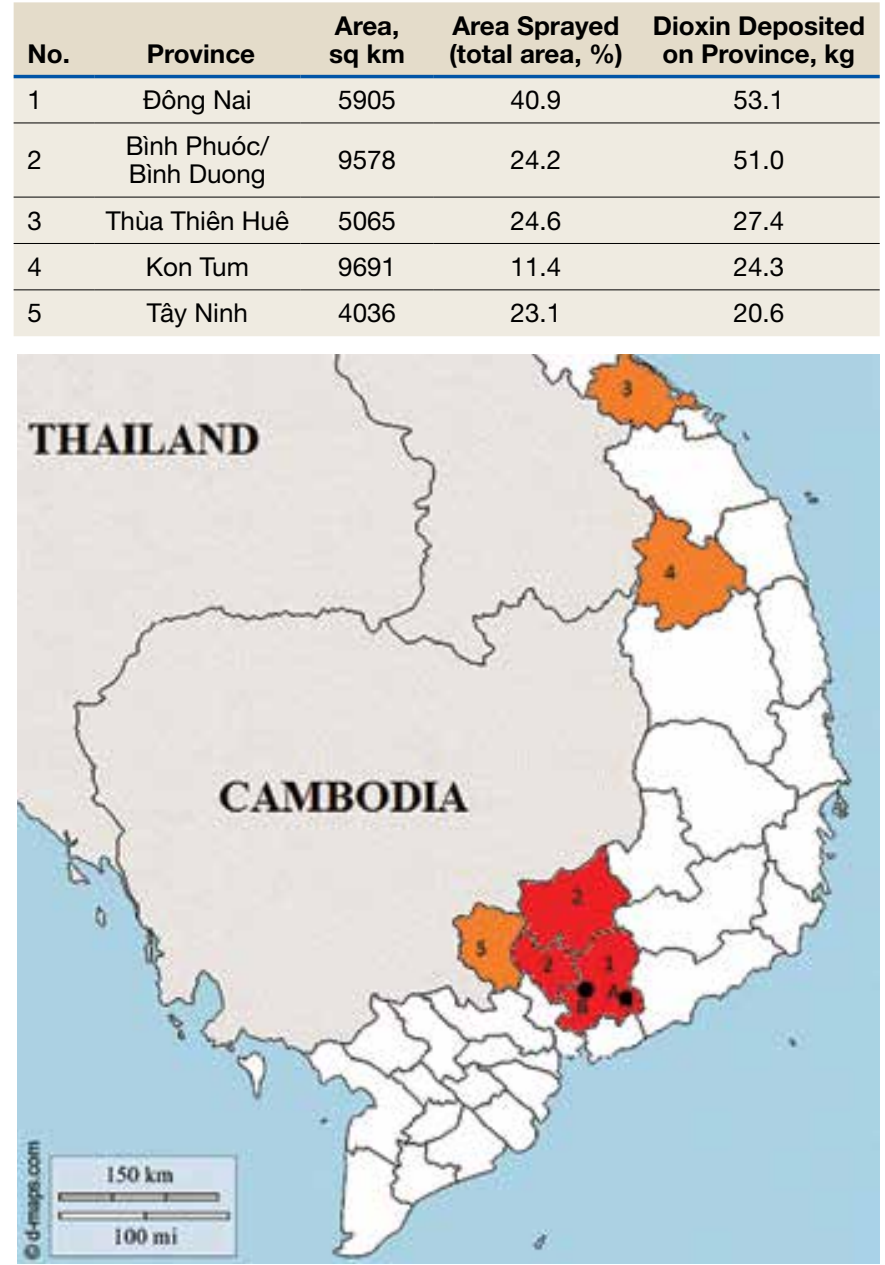

Most heavily sprayed regions: red, 1 and 2; orange, 3, 4, and 5 . Service members' deployment locations: A, Xuan Loc; B, Bien Hua and Long Binh. aMap adapted from d-maps.com.

The patient's 3 arterial grafts in his left leg were confirmed to have failed, and the patient was counseled that he would soon likely require an amputation of his ischemic leg.

\section{DISCUSSION}

We must rely on our patient's historical recall as there are no widely available laboratory tests or physical examination findings to confirm and/ or determine the magnitude of TCDD or arsenic exposure. ${ }^{9-11}$

\section{Exposures}

The patient was stationed in Bien Hoa, the second highest dioxin-contaminated air base in Vietnam (Figure). ${ }^{6}$ Dioxin also is known to be a particularly persistent environmental pollutant, such that in January 2018, Bien Hoa 
TABLE 1 Qualities of Evidence, for Associations of Agent Orange Exposure With Disease for Veterans ${ }^{5}$

\begin{tabular}{ll} 
Levels of Evidence & Description \\
\hline Sufficient & $\begin{array}{l}\text { Epidemiologic evidence sufficient to conclude positive } \\
\text { association with reasonable confidence that chance, bias, } \\
\text { and confounding variables may be ruled out. }\end{array}$ \\
\hline Limited or suggestive & $\begin{array}{l}\text { Epidemiologic evidence suggestive of association without } \\
\text { ability to rule out chance, bias, and confounding variables } \\
\text { with confidence. }\end{array}$ \\
\hline $\begin{array}{l}\text { Inadequate or } \\
\text { insufficient }\end{array}$ & $\begin{array}{l}\text { The available epidemiologic studies are inconclusive due } \\
\text { to lack of quality, consistency, statistical power. }\end{array}$ \\
\hline $\begin{array}{l}\text { Limited or suggestive } \\
\text { of no association }\end{array}$ & $\begin{array}{l}\text { Based on several adequate studies, there is limited or } \\
\text { suggestive evidence of no association between exposure } \\
\text { to the herbicide components of interest and health } \\
\text { outcome. }\end{array}$
\end{tabular}

was found to still have dioxin levels higher than what is considered internationally acceptable. In fact, these levels were deemed significant enough to lead the United States and Vietnamese government to sign a memorandum of intent to begin cleanup of this airport. ${ }^{6} \mathrm{TCDD}$ is known to have a half-life of about 7.6 years, and its long half-life is mainly attributed to its slow elimination process from its stores within the liver and fat, consisting of passive excretion through the gut wall and slow metabolism by the liver..$^{12,13}$ Thus, as an artilleryman mainly operating 105 howitzers within the foliage of Vietnam, our patient was exposed not only to high levels of this persistent environmental pollutant on a daily basis, but this toxin likely remained within his system for many years after his return from Vietnam.

Our patient also had a convincing history for potential Agent Blue exposure through both inhalation and ingestion of contaminated food and water. Additionally, his description of deforestations occurring within a matter of days increased the level of suspicion for Agent Blue exposure. This is because Agent Blue was the herbicide of choice for missions requiring rapid deforestation, achieving defoliation as quickly as 1 to 2 days. ${ }^{14}$ Additionally, our patient was stationed within cities in southern Vietnam near Agent Blue hot spots, such as Da Nang and Saigon, and Agent Blue was sprayed along the perimeter of all military bases. ${ }^{2}$

\section{Levels of Evidence}

Using the Veterans and Agent Orange Update in 2018 as our guide, we reviewed the quality of evidence suggesting an association between many of our patient's comorbidities to Agent Orange exposure. ${ }^{5}$ This publication categorizes the level of evidence for association between health conditions and Agent Orange exposure in 4 main categories (Table 1).

In the Veterans and Agent Orange Update, $\mathrm{NHL}$ notably has a sufficient level of evidence of association with Agent Orange exposure. ${ }^{5}$ Although our patient's extensive history of polysubstance use confounds the effect Agent Orange may have had on his health, cutaneous large B-cell NHL is an interesting exception as literature does not support even a correlative link between smoking and excessive alcohol use with primary cutaneous large B-cell NHL. Several case-control studies have found little to no association with cigarette smoking and the large B-cell subtype of NHL. ${ }^{15,16}$ Moreover, several studies have found that moderate- toheavy alcohol use, especially beer, may have a protective effect against the development of $\mathrm{NHL} .{ }^{17}$ Of note, our patient's alcoholic beverage of choice was beer. Regarding our patient's distant history of cocaine use, it has been reported that cocaine use, in the absence of an HIV infection, has not been found to increase the risk of developing NHL. ${ }^{18}$ Similarly, arsenic exposure has not been associated with NHL in the literature..$^{19,20}$

The 2018 update also upgraded bladder carcinoma from having inadequate or insufficient to a limited or suggestive level of evidence for association. ${ }^{5}$ However, our patient's most significant risk factor for bladder cancer was smoking, with a meta-analysis of 430,000 patients reporting a risk ratio (RR) of 3.14 for current cigarette smokers. ${ }^{21}$ The patient's arsenic exposure from Agent Blue also increased his risk of developing bladder cancer. Several studies suggest a strong association between environmental arsenic exposure and bladder cancer. ${ }^{22-26}$ A 30-year meta-analysis of 40 studies by Saint-Jacques and colleagues reported that the incidence of bladder cancer was found to increase in a dose-dependent manner, with higher concentrations of arsenic contaminated wate, with incidence rising from 2.7 to 5.8 times as the amount of arsenic contamination water increased from 10 to $150 \mathrm{mg} / \mathrm{L}$.

Our patient's history is concerning for higher than average Agent Blue exposure compared with that of most Vietnam War veterans. Given 
TABLE 2 Conditions Veterans With Exposure to Agent Orange May Be Entitled Compensation for as of May 2019, and Level of Evidence for Association ${ }^{5,23}$

\begin{tabular}{|c|c|c|c|}
\hline Investigated Conditions & Associated Levels of Evidence & Compensation Eligibility & Patient Case \\
\hline Chronic B-cell leukemias & Sufficient & Yes & \\
\hline Chloracne & Sufficient & Yes & \\
\hline Hodgkin disease & Sufficient & Yes & \\
\hline Non-Hodgkin lymphoma & Sufficient & Yes & Yes \\
\hline $\begin{array}{l}\text { Soft tissue sarcomas (other than osteosarcoma, } \\
\text { chondrosarcoma, Kaposi sarcoma, or mesothelioma) }\end{array}$ & Sufficient & Yes & \\
\hline Monoclonal gammopathy of undetermined significance & Sufficient & No & \\
\hline Hypertension & Sufficient & No & Yes \\
\hline Type 2 diabetes mellitus & $\begin{array}{l}\text { No consensus } \\
\text { (sufficient vs limited) }\end{array}$ & Yes & Yes \\
\hline Bladder cancer & Limited or suggestive & No & Yes \\
\hline Multiple myeloma & Limited or suggestive & Yes & \\
\hline Prostate cancer & Limited or suggestive & Yes & \\
\hline Respiratory cancers (lung, larynx, trachea, bronchus) & Limited or suggestive & Yes & \\
\hline Amyloid light-chain amyloidosis & Limited or suggestive & Yes & Yes \\
\hline Hypothyroidism & Limited or suggestive & No & \\
\hline Ischemic heart disease & Limited or suggestive & Yes & Yes \\
\hline Parkinson disease & Limited or suggestive & Yes & \\
\hline Peripheral neuropathy, early onset & Limited or suggestive & Yes & \\
\hline Porphyria cutanea tarda & Limited or suggestive & Yes & \\
\hline
\end{tabular}

the dose-dependent effect of arsenic on bladder cancer risk, both our patient's history of smoking and Agent Blue exposure are risk factors in the development of his bladder cancer. ${ }^{22}$ These likely played a more significant role in his development of bladder cancer than did his Agent Orange exposure.

Finally, smoking is the most significant risk factor in our patient's development of anal carcinoma in situ. The 2018 Agent Orange update does report limited/suggested evidence of no association between Agent Orange and anal carcinoma. ${ }^{5}$ It also is unknown whether Agent Blue exposure is a contributing cause to his development of anal carcinoma in situ. ${ }^{27}$ However, current smokers are at significant risk of developing anal cancer independent of age. ${ }^{28-30}$ Given our patient's extensive smoking history, this is the most likely contributing factor.

Our patient also had several noncancerrelated comorbidities with correlative associations with Agent Orange exposure of varying degrees (Table 2). Somewhat surprising, the development of our patient's hypertension and T2DM may be associated in some way with his history of Agent Orange exposure. Hypertension had been recategorized from having limited or suggestive evidence to sufficient evidence in this committee's most recent publication, and the committee is undecided on whether T2DM has a sufficient vs limited level of evidence for association with Agent Orange exposure. ${ }^{5}$ On the other hand, the committee continues to classify both ischemic heart disease and $A L$ amyloidosis as having a limited or suggestive level of evidence that links Agent Orange exposure to these conditions. ${ }^{5}$

Arsenic may be another risk factor for our patient's development of CAD and arterial insufficiency. Arsenic exposure is theorized to cause a direct toxic effect on coronary arteries, and arsenic exposure has been linked to PAD, CAD, and hypertension. ${ }^{31-34}$ Other significant and compelling risk factors for cardiovascular disease in our patient included his extensive history of heavy cigarette smoking, poorly controlled T2DM, obesity, and hypertension. ${ }^{35-37} \mathrm{AL}$ amyloidosis is a rare 
disorder with an incidence of only 9 to 14 cases per million person-years. ${ }^{38,39}$ This disorder has not been linked to smoking or arsenic exposure in the literature. As our patient does not have a history of plasma dyscrasias or a family history of $A L$ amyloidosis, the only known risk factors for $\mathrm{AL}$ amyloidosis that apply to our patient included $\mathrm{NHL}$ and Agent Orange exposure-NHL being a condition that is noted to be strongly correlated with Agent Orange exposure as discussed previously. $5,36,40,41$

\section{CONCLUSIONS}

This case describes a Vietnam War veteran with significant exposure to rainbow herbicides and considerable polysubstance who developed 3 primary cancers and several chronic medical conditions. His exposure to Agents Orange and Blue likely contributed to his medical problems, but these associations are confounded by his substance use, particularly cigarette smoking. Of all his comorbidities, our patient's NHL is the condition most likely to be associated with his history of Agent Orange exposure. His Agent Blue exposure also increased his risk for developing bladder cancer, cardiovascular disease, and PAD.

This case also highlights the importance of evaluating Vietnam War veterans for rainbow herbicide exposure and the complexity associated with attributing diseases to these exposures. All veterans who served in the inland waterways of Vietnam between 1962 and 1975; in the Korean Demilitarized Zone between April 1, 1968 and August 31, 1971; or in Thailand between February 28, 1961 and May 7, 1975 were at risk of rainbow herbicide exposure. These veterans may not only be eligible for disability compensation but also should be screened for associated comorbidities as outlined by current research. ${ }^{42}$ We hope that this report will serve as an aid in achieving this mission.

\section{Author disclosures}

The authors report no actual or potential conflicts of interest with regard to this article.

\section{Disclaimer}

The opinions expressed herein are those of the authors and do not necessarily reflect those of Federal Practitioner, Frontline Medical Communications Inc., the US Government, or any of its agencies. This article may discuss unlabeled or investigational use of certain drugs. Please review the complete prescribing information for specific drugs or drug combinations-including indications, contraindications, warnings, and adverse effects-before administering pharmacologic therapy to patients.

\section{References}

1. Stellman JM, Stellman SD, Christian R, Weber T, Tomasallo C. The extent and patterns of usage of Agent Orange and other herbicides in Vietnam. Nature. 2003;422(6933):681687. doi:10.1038/nature01537

2. Olson K, Cihacek L. The fate of Agent Blue, the arsenic based herbicide, used in South Vietnam during the Vietnam War. Open J Soil Sci. 2020;10:518-577. doi:10.4236/ojss.2020.1011027

3. Lee Chang A, Dym AA, Venegas-Borsellino $C$, et al. Comparison between simulationbased training and lecture-based education in teaching situation awareness. a randomized controlled study. Ann Am Thorac Soc. 2017;14(4):529-535. doi:10.1513/AnnalsATS.201612-9500C

4. Stellman SD. Agent Orange during the Vietnam War: the lingering issue of its civilian and military health impact. Am J Public Health. 2018;108(6):726-728. doi:10.2105/AJPH.2018.304426

5. National Academies of Sciences, Engineering, and Medicine. Veterans and Agent Orange: Update 11 (2018). The National Academies Press; 2018. doi:10.17226/25137

6. Martin MF. US Agent Orange/dioxin assistance to Vietnam. Updated January 15, 2021. Accessed June 17, 2021. https://fas.org/sgp/crs/row/R44268.pdf

7. Saha JC, Dikshit AK, Bandyopadhyay M, Saha KC. A review of arsenic poisoning and its effects on human health. Crit Rev Environ Sci Technol. 1999;29(3):281-313. doi:10.1080/10643389991259227

8. Siegel RL, Miller KD, Jemal A. Cancer statistics, 2019. CA Cancer J Clin. 2019;69(1):7-34. doi:10.3322/caac.21551

9. American Cancer Society. Agent Orange and cancer risk. Updated June 9, 2020. Accessed June 17, 2021. https:// www.cancer.org/cancer/cancer-causes/agent-orange -and-cancer.html

10. US Department of Veterans Affairs. Veterans' diseases associated with Agent Orange. Updated June 16, 2021. Accessed June 17, 2021. https://www.publichealth.va.gov /exposures/agentorange/conditions/index.asp

11. Katz SA. On the use of hair analysis for assessing arsenic intoxication. Int J Environ Res Public Health. 2019;16(6):977. Published 2019 Mar 18. doi:10.3390/ijerph16060977

12. Chang ET, Boffetta P, Adami HO, Mandel JS. A critical review of the epidemiology of Agent Orange or 2,3,7,8-tetrachlorodibenzo-p-dioxin and lymphoid malignancies. Ann Epidemiol. 2015;25(4):275-292.e30. doi:10.1016/j.annepidem.2015.01.002

13. Kramárová $\mathrm{E}$, Kogevinas $\mathrm{M}$, Anh $\mathrm{CT}$, et al. Exposure to Agent Orange and occurrence of soft-tissue sarcomas or non-Hodgkin lymphomas: an ongoing study in Vietnam. Environ Health Perspect. 1998;106 Suppl 2(suppl 2):671678. doi:10.1289/ehp.106-1533419

14. Institute of Medicine (US) Committee to Review the Health Effects in Vietnam Veterans of Exposure to Herbicides. Veterans and Agent Orange: Health Effects of Herbicides Used in Vietnam. National Academies Press US; 1994.

15. Morton LM, Hartge P, Holford TR, et al. Cigarette smoking and risk of non-Hodgkin lymphoma: a pooled analysis from the International Lymphoma Epidemiology Consortium (interlymph). Cancer Epidemiol Biomarkers Prev. 2005;14(4):925-933. doi:10.1158/1055-9965.EPI-04-0693

16. Schöllkopf $\mathrm{C}$, Smedby KE, Hjalgrim $\mathrm{H}$, et al. Cigarette smoking and risk of non-Hodgkin's Iymphoma-a population-based case-control study. Cancer Epidemiol Biomarkers Prev. 2005;14(7):1791-1796. doi:10.1158/1055-9965.EPI-05-0077

17. Psaltopoulou T, Sergentanis TN, Ntanasis-Stathopoulos I, Tzanninis IG, Tsilimigras DI, Dimopoulos MA. Alcohol consumption and risk of hematological malignancies: a meta-analysis of prospective studies. Int J Cancer. 2018;143(3):486-495. doi:10.1002/ijc.31330

18. Aujla AS, Lee SH. Association between cocaine use and hematological malignancies. J Clin Oncol. 2016;34(15_suppl):e19072-e19072. 
doi:10.1200/JCO.2016.34.15 suppl.e19072

19. Mao Y, Hu J, Ugnat AM, White K. Non-Hodgkin's Iymphoma and occupational exposure to chemicals in Canada. Canadian Cancer Registries Epidemiology Research Group. Ann Oncol. 2000;11 (suppl 1):69-73. doi:10.1093/annonc/11.suppl_1.S69

20. Kelekci KH, Bilgin I, Ermete M. Arsenical keratoses and non-Hodgkin's lymphoma: arsenic-induced or coincidental conditions? J Pakistan Assoc Dermatol. 2012;22(4): 366-369.

21. Antoni S, Ferlay J, Soerjomataram I, Znaor A, Jemal A, Bray F. Bladder cancer incidence and mortality: a global overview and recent trends. Eur Urol. 2017;71(1):96-108. doi:10.1016/j.eururo.2016.06.010

22. Saint-Jacques N, Parker L, Brown P, Dummer TJ. Arsenic in drinking water and urinary tract cancers: a systematic review of 30 years of epidemiological evidence. Environ Health. 2014;13:44. Published 2014 Jun 2. doi:10.1186/1476-069X-13-44

23. Radosavljevic V, Jakovljevic B. Arsenic and bladder cancer: observations and suggestions. $J$ Environ Health. 2008;71(3):40-42.

24. Marsit CJ, Karagas MR, Schned A, Kelsey KT. Carcinogen exposure and epigenetic silencing in bladder cancer. Ann N Y Acad Sci. 2006;1076(1):810-821. doi:10.1196/annals.1371.031

25. Mendez WM Jr, Eftim S, Cohen J, et al. Relationships between arsenic concentrations in drinking water and lung and bladder cancer incidence in U.S. counties. J Expo Sci Environ Epidemiol. 2017;27(3):235-243. doi:10.1038/jes.2016.58

26. Pal DK, Agrawal A, Ghosh S, Ghosh A. Association of arsenic with recurrence of urinary bladder cancer. Trop Doct. 2020;50(4):325-330. doi:10.1177/0049475520930155

27. García-Esquinas E, Pollán M, Umans JG, et al. Arsenic exposure and cancer mortality in a US based prospective cohort: the strong heart study [published correction appears in Cancer Epidemiol Biomarkers Prev. 2013;22(8):1479]. Cancer Epidemiol Biomarkers Prev. 2013;22(11):1944-1953. doi:10.1158/1055-9965.EPI-13-0234-T

28. Daling JR, Madeleine MM, Johnson LG, et al. Human papillomavirus, smoking, and sexual practices in the etiology of anal cancer. Cancer. 2004;101(2):270-280. doi:10.1002/cncr.20365

29. Bertisch B, Franceschi S, Lise M, et al; Swiss HIV Cohort Study Investigators. Risk factors for anal cancer in persons infected with HIV: a nested case-control study in the Swiss HIV Cohort Study. Am J Epidemiol. 2013;178(6):877-884. doi:10.1093/aje/kwt153

30. Rabkin CS, Biggar RJ, Melbye M, Curtis RE. Second primary cancers following anal and cervical carcinoma: evidence of shared etiologic factors. Am J Epidemiol 1992;136(1):54-58. doi:10.1093/oxfordjournals.aje.a116420

31. Newman JD, Navas-Acien A, Kuo CC et al. Peripheral arterial disease and its association with arsenic exposure and metabolism in the Strong Heart Study. Am J Epidemiol. 2016;184(11):806-817. doi:10.1093/aje/kww002

32. Moon KA, Guallar E, Umans JG, et al. Association between exposure to low to moderate arsenic levels and incident cardiovascular disease. A prospectivecohortstudy.AnnInternMed.2013;159(10):649-659. doi:10.7326/0003-4819-159-10-201311190-00719

33. Moon K, Guallar E, Navas-Acien A. Arsenic exposure and cardiovascular disease: an updated systematic review. Curr Atheroscler Rep. 2012;14(6):542-555. doi:10.1007/s11883-012-0280-x

34. Stea F, Bianchi F, Cori L, Sicari R. Cardiovascular effects of arsenic: clinical and epidemiological findings. Environ Sci Pollut Res Int. 2014;21(1):244-251. doi:10.1007/s11356-013-2113-z

35. Burns DM. Epidemiology of smoking-induced cardiovascular disease. Prog Cardiovasc Dis. 2003;46(1):11-29. doi:10.1016/s0033-0620(03)00079-3

36. Merlini G, Dispenzieri A, Sanchorawala V, et al. Systemic immunoglobulin light chain amyloidosis. Nat Rev Dis Primers. 2018;4(1):38. Published 2018 Oct 25. doi:10.1038/s41572-018-0034-3

37. Dokken BB. The pathophysiology of cardiovascular disease and diabetes: beyond blood pressure and lipids. Diabetes Spectrum. 2008;21(3):160-165. doi:10.2337/diaspect.21.3.160

38. Vaxman I, Gertz M. Recent advances in the diagnosis, risk stratification, and management of systemic lightchain amyloidosis. Acta Haematol. 2019;141(2):93-106. doi:10.1159/000495455

39. Quock TP, Yan T, Chang E, Guthrie S, Broder MS. Epidemiology of $A L$ amyloidosis: a real-world study using US claims data. Blood Adv. 2018;2(10):1046-1053. doi:10.1182/bloodadvances.2018016402

40. Basset M, Defrancesco I, Milani P, et al. Nonlymphoplasmacytic lymphomas associated with lightchain amyloidosis. Blood. 2020;135(4):293-296. doi:10.1182/blood.2019002762

41. Kyle RA, Therneau TM, Rajkumar SV, et al. A long-term study of prognosis in monoclonal gammopathy of undetermined significance. N Engl J Med. 2002;346(8):564-569. doi:10.1056/NEJMoa01133202

42. US Department of Veterans Affairs. Agent Orange registry health exam for veterans. Updated May 28, 2021. Accessed June 17, 2021. https://www.publichealth.va.gov /exposures/agentorange/benefits/registry-exam.asp 